\title{
Methacholine inhalation challenge: a shorter, cheaper and safe approach
}

\author{
G. Izbicki, E. Bar-Yishay
}

\begin{abstract}
Methacholine inhalation challenge: a shorter, cheaper and safe approach. G. Izbicki, E. Bar-Yishay. C) ERS Journals Ltd 2001.

ABSTRACT: Increased nonspecific bronchial hyperresponsiveness to pharmacological agents such as histamine or methacholine (MCh) is a hallmark of asthma. The measurement of airway reactivity is quite sensitive but testing is tedious, and time and money consuming. The present aim was, therefore, to design the shortest possible, yet safe inhalation challenge protocol applicable for a lung function referral centre.

All records of studies performed in our institution during 1996 were analyzed retrospectively with a baseline ratio (bl) of forced expiratory volume in one second/ forced vital capacity $(\mathrm{FEV} 1 / \mathrm{FVC}) \geqslant 0.7(\mathrm{n}=449)$. It was questioned what the initial dose should be, and whether some inhalation steps could have been skipped without losing pertinent information and/or causing an adverse response (a fall in FEV1 $>40 \%$ ). When unavailable, provocative dose causing a $20 \%$ fall in FEV1 (PD20) values were obtained by linear inter- or extrapolation of the existing data.

The present study showed that three-fold concentration steps could have been employed with minimal change in outcome. Only $15 / 449$ patients $(3.3 \%)$ would have experienced a severe response. Five subjects (of 169, 3.0\%) with FEV1/FVCbl 0.7-0.8 reacted to inhalation up to $0.073 \mu \mathrm{mol}$. Four subjects (of $280,1.4 \%$ ) with FEV1/ FVCbl $\geqslant 0.8$ reacted to inhalation up to $0.219 \mu \mathrm{mol}$.

The authors suggest that: 1 ) an initial dose of $0.219 \mu \mathrm{mol}$ (initial concentration= $0.21 \mathrm{mg} \cdot \mathrm{mL}^{-1}$ ) may be used when the baseline ratio of forced expiratory volume in one second to forced vital capacity $\geqslant 0.8$ and $0.073 \mu \mathrm{mol}$ (initial concentration $=0.07$ $\mathrm{mg} \cdot \mathrm{mL}^{-1}$ ) when the baseline ratio is $<0.8 ; 2$ ) a tripling dose protocol is easier to perform, cheaper and $30.2 \%$ faster, yet just as safe; and 3 ) other abbreviated protocols used in epidemiologic settings may not be applicable in a referral centre setting.

Eur Respir J 2001; 17: 46-51.
\end{abstract}

Methacholine $(\mathrm{MCh})$ or histamine inhalation challenge tests are often used to generate dose-response curves and measure nonspecific bronchial hyperresponsiveness. The method is quite sensitive [1], but is tedious, and time and money consuming. In Hadassah University hospital, MCh challenge tests are performed according to a modified method of CHAI et al. [2] and COCKCROFT et al. [3]. They often take over one hour to complete and cost over $\$ 100$ in Israel.

Several short protocols for bronchial provocation testing have been proposed in the past 20 yrs [4-12]. The biggest disadvantage of any proposed protocol is the risk of developing marked airways obstruction i.e. a fall $>40 \%$ in forced expiratory volume in one second (FEV1) [4, 8-10, 12]. For example, in the protocol suggested by CHATHAM et al. [10], as many as $38.5 \%$ of subjects actually developed such a marked obstruction. In addition, abbreviated protocols may be safe when applied in random populations, but may not be as safe for a referral pulmonary function centre.

Furthermore, any comparison of results obtained from a pair of challenges needed in a prospective design, is prone to errors since between-test variability is in the order of magnitude of one doubling
Institute of Pulmonology, Hadassah University Hospital, Hebrew University-Hadassah Medical School, Jerusalem, Israel.

\author{
Correspondence: E. Bar-Yishay \\ Institute of Pulmonology \\ Hadassah University Hospital \\ Hebrew University-Hadassah Medical \\ School \\ P.O. Box 12000 \\ Jerusalem 91120 \\ Israel \\ Fax: 97226435897
}

Keywords: Abbreviated, bronchial challenge test, methacholine, protocol

Received: July 61999

Accepted after revision July 252000

This research was supported by grants from the Israel Lung Association and from the Swiss National Scientific Foundation (No. 81GE-05006), the Swiss Society of Pulmonology and the Freiwillige Akademische Gesellschaft. concentration [11]. In contrast, a retrospective analysis is a better approach for the question at hand since each subject serves as their own control within the same challenge. Additionally, any abbreviated protocol can be tested on as many records as possible and without affecting the subjects. Thus, the present analysis allowed the authors to calculate the added risks involved in simulated protocols starting at a higher initial dose, and in shortening the protocol by widening the steps between inhalations, without putting the subject at risk.

To the best of the authors' knowledge, there is no study based on a retrospective analysis which tests the feasibility and safety of a short MCh provocation test in a referral pulmonary function centre. The purpose of this study was to design the shortest possible, yet safe methacholine challenge test (MCT) protocol to measure nonspecific airways reactivity.

\section{Subjects and methods}

A retrospective analysis of all 487 records of patients who underwent an MCT in the authors' institution, was performed during 1996. Anthropometric data of the 
Table 1. - Patient anthropometric data and baseline values

\begin{tabular}{|c|c|c|c|}
\hline & \multicolumn{2}{|c|}{ FEV1/FVCbl } & \multirow{2}{*}{ Total } \\
\hline & $\geqslant 0.8$ & $<0.8$ & \\
\hline Subjects n & 280 & 169 & 449 \\
\hline Male & $153(55)$ & $94(56)$ & $247(55)$ \\
\hline Age yrs & $19(6-72)$ & $26(7-84)$ & $19(6-84)$ \\
\hline FEV1 $\%$ pred & $94.3 \pm 11.3$ & $88.9 \pm 12.7$ & $92.2 \pm 11.9$ \\
\hline FEF50\% pred & $94.3 \pm 18.4$ & $66.2 \pm 12.9$ & $83.7 \pm 21.3$ \\
\hline Positive responders & $155(55.4)$ & $113(66.7)$ & $268(59.7)$ \\
\hline PD20 $\mu \mathrm{mol}^{*}$ & $1.50(0.14-17.05)$ & $0.94(0.05-17.31)$ & $1.24(0.08-17.82)$ \\
\hline
\end{tabular}

Data presented as mean \pm SD, n $(\%)$ or mean (range), except where stated. FEV1: forced expiratory volume in one second; FEV1/FVCbl: baseline ratio of FEV1 to forced vital capacity; \% pred: percentage of the predicted value; FEF50: forced expiratory flow at $50 \%$ of vital capacity; PD20: provocative dose causing a $20 \%$ fall in FEV1; *: data presented as geometric mean $(95 \%$ confidence interval).

population studied are presented in table 1. Most were referred as part of routine investigation of suspected asthmatics, based on clinical signs such as wheezing, dyspnoea, prolonged cough, and atopy, or for reevaluation of known asthmatics. Thirty-eight of the patients underwent the challenge test despite the fact that they had a baseline ratio of forced expiratory volume to forced vital capacity $(\mathrm{FEV} 1 / \mathrm{FVCbl}) \leqslant 0.7$. Normally, this condition precludes routine testing and, therefore, these patients were omitted from further analysis.

\section{Routine methacholine challenge test protocol}

MCTs have been routinely carried out in the Hadassah University Hospital using the modified method of CHAI et al. [2] and CocKCrofT et al. [3] i.e. the $2 \mathrm{~min}$ tidal breathing [3] and the doubling concentrations step-up [2]. Starting concentration is $0.03 \mathrm{mg} \cdot \mathrm{mL}^{-1}$ for all the patients. FVC manoeuvres are performed using an electronic spirometer (Compact, Vitalograph Ltd, Buckingham, UK). The MCT was performed provided that baseline $\mathrm{FEV} 1 \geqslant 60 \%$ predicted and $\mathrm{FEV} 1 / \mathrm{FVCbl}>0.7$. A complete test consists of inhaling phosphate buffered solution and then doubling concentrations of MCh (Spectrum Quality Products, Inc., CA, USA), starting at $0.031 \mathrm{mg} \cdot \mathrm{mL}^{-1}$ and up to $8.0 \mathrm{mg} \cdot \mathrm{mL}^{-1}$. At each step, the patient breathes tidally for $2 \mathrm{~min}$ from a nebulizer (Respigard II nebulizer System, Marquest Medical Products Inc., NJ, USA) having an output of $0.34 \mathrm{~mL} \cdot \mathrm{min}^{-1}$. Spirometry is performed in duplicates $1 \mathrm{~min}$ after the inhalation, as suggested by YAN et al. [4], the best FEV1 value is recorded, and the percentage change in FEV1 from baseline $(\triangle F E V 1)$ is calculated. If $\triangle F E V 1<15 \%$, the test proceeds to the next step. When the response is borderline $(\triangle \mathrm{FEV} 115-20 \%)$ the next inhalation given is half the next doubling concentration. The test continues until a positive response $($ i.e. $\triangle \mathrm{FEV} 1 \geqslant 20 \%)$ is observed or when the final concentration is reached. The provocative dose causing a $\triangle \mathrm{FEV} 1$ of $20 \%$ (PD20) is calculated by linear interpolation of the last two responses.

In order for the results to be comparable with other publications, cumulative doses are presented in $\mu \mathrm{mol}$ delivered. Using our nebulizer output $\left(0.34 \mathrm{~mL} \cdot \mathrm{min}^{-1}\right)$, time of inhalation ( 2 mins), and the duty cycle for tidal breathing (assumed at 0.3), the conversion factor suitable for the centre was calculated based on the following relationship: delivered dose $(\mu \mathrm{mol})=$ factor $\left(\mu \mathrm{mol} \cdot \mathrm{mg} \cdot \mathrm{mL}^{-1}\right) \cdot$ concentration $\left(\mathrm{mg} \cdot \mathrm{mL}^{-1}\right)$ factor $(\mu \mathrm{mol}$. $\left.\mathrm{mg}^{-1} \cdot \mathrm{mL}\right)=$ molecular weight $\left(\mu \mathrm{mol} \cdot \mathrm{mg}^{-1}\right) \cdot$ nebulizer output $\left(\mathrm{mL} \cdot \mathrm{min}^{-1}\right) \cdot$ time of inhalation $(\mathrm{min})$ molecular weight of $\mathrm{MCh}=195.7\left(\mathrm{~g} \cdot \mathrm{mol}^{-1}\right)$ factor $\left(\mu \mathrm{mol} \cdot \mathrm{mg}^{-1}\right.$. $\mathrm{mL})=5.1098\left(\mu \mathrm{mol} \cdot \mathrm{mg}^{-1}\right) \cdot 0.34\left(\mathrm{~mL} \cdot \mathrm{min}^{-1}\right) \cdot 2(\mathrm{~min}) \cdot 0.3=$ 1.042 .

Hence, the dose given in $\mathrm{mg} \cdot \mathrm{mL}^{-1}$ was converted to $\mu \mathrm{mol}$, delivered by a factor of 1.042 . The concentrations used were $0.03-8 \mathrm{mg} \cdot \mathrm{mL}^{-1}$ and the doses actually delivered were $0.032-8.34 \mu \mathrm{mol}$.

\section{Study design}

All past records were reviewed and cumulative doses at each step were calculated. The authors then simulated various abbreviated protocols (i.e. three-fold dose steps, four-fold, and so on) on each record to see what would have been that subject's response had they been exposed to the stipulated design. Values were calculated by linear interpolation or extrapolation of the available data at the nearest two inhalations.

\section{Statistical analysis}

Comparisons were made by paired, unpaired t-tests and by the Chi-squared test, and differences were considered significant at $\mathrm{p}<0.05$ level. As PD20 values are logarithmically distributed, mean values $(95 \%$ confidence interval (CI)) were calculated after log transformation. The analyses performed in this work stem from the authors' attempt to answer the following three questions. What is an acceptable risk? The authors' a priori assumption was that the risk currently acceptable when performing the full protocol should be acceptable for any abbreviated protocol. This risk factor was determined by reviewing all 268 records in which a positive response i.e. $\triangle \mathrm{FEV} 1 \geqslant 20 \%$, was observed. Despite all the necessary precautions taken when running the routine (and supposedly safest) protocol, 57 subjects $(20.9 \%)$ developed a moderate response i.e. $\triangle \mathrm{FEV} 1>30 \%$, and 11 subjects $(4.1 \%)$ 
developed marked airways obstruction i.e. $\triangle \mathrm{FEV} 1$ $>40 \%$. Hence, the authors decided to use this latter threshold as an acceptable risk factor of developing a marked airway obstruction for comparison with present results. What should be the initial MCh dose? Reviewing all past records, the number of positive responses at each successive step were counted and the accumulated percentage of occurrence was compared to risk factor. That is, the number of subjects who would have been at risk had the test been started at an MCh dose higher than that at which they had responded, was determined. What is the optimal dose-multiplier? As previously described, the authors ran simulations of various abbreviated protocols and counted the number of positive responses at each higher dose. The optimal step was thus determined when the number of responses (per cent occurrence) reached the level of acceptable risk i.e. $4.0 \%$, as previously determined. Once the new step was determined, the results of each subject were interpolated or extrapolated to this inhalation step in order to determine the subject's response had they been studied by the abbreviated protocol.

\section{Results}

A total of 487 records were reviewed but only those with an $\mathrm{FEV} 1 / \mathrm{FVCbl}>0.7 \quad(\mathrm{n}=449)$ were analyzed (table 1). According to American Thoracic Society recommendations, $\mathrm{FEV} 1 / \mathrm{FVCbl}$ is an important parameter to distinguish an obstructive impairment [13]. Therefore, the subjects were divided according to their baseline values, with 169 subjects $(37.6 \%)$ having FEV1/ FVCbl $<0.8$ and 280 with FEV1/FVCbl $\geqslant 0.8 \%$. Twohundred and sixty-eight subjects $(59.7 \%)$ had a positive response to $\mathrm{MCh}$ at or before reaching the final dose of $17.73 \mu \mathrm{mol}$ (concentration of $8 \mathrm{mg} \cdot \mathrm{mL}^{-1}$ ). Baseline values of $\mathrm{FEV} 1$ were similar but forced expiratory flow rate at $50 \%$ vital capacity (FEF50) were significantly lower in the FEV1/FVCbl $<0.8$ group $(\mathrm{p}<0.0001)$. The per cent of responders in this group was higher (Chi-squared test, $\mathrm{p}<0.05)$ and PD20 lower $(\mathrm{p}<0.05)$.

\section{What should be the initial dose?}

Only five of 169 subjects $(3 \%)$ with $\mathrm{FEV} 1 / \mathrm{FVCbl}<0.8$ had a PD20 $<0.073 \mu \mathrm{mol}$ and only two of them (table 2) had a positive response to a lower inhalation dose i.e. $0.033 \mu \mathrm{mol}$. When inter- or extrapolating their data to the suggested initial step of $0.073 \mu \mathrm{mol}$, two of the subjects would have developed a severe response (out of $169,1.2 \%$ ) (table 3 ). Only four of 280 subjects $(1.4 \%)$ with $\mathrm{FEV} 1 / \mathrm{FVCbl} \geqslant 0.8$ had a PD20 $<0.219 \mu \mathrm{mol}$, and only one of them had a positive response to a lower inhalation. None of the subjects would have presented a severe response (table 3 ). Thus, it is suggested that the initial dose for routine $\mathrm{MCh}$ challenges for subjects having $\mathrm{FEV} 1 / \mathrm{FVCbl} \geqslant 0.8$ (constituting approximately two-thirds of the sample) need not be less than $0.219 \mu \mathrm{mol}$. It is further suggested that subjects having $\mathrm{FEV} 1 / \mathrm{FVCb}<0.8$ need not be challenged at a dose $<0.073 \mu \mathrm{mol}$ (fig. 1).

\section{What is the optimal dose-multiplier?}

Having determined a prevalence of $4.1 \%$ of severe response (i.e. $\triangle \mathrm{FEV} 1>40 \%$ ) as an acceptable risk, the authors determined the three-fold dose-multiplier to be the optimal protocol (table 2). Eight of the subjects with $\mathrm{FEV} 1 / \mathrm{FVCbl}<0.8$ had PD20 0.073-0.219 $\mu \mathrm{mol}$ and one responded at an intermediate step. None of the subjects would have presented with an extrapolated severe response at $0.219 \mu \mathrm{mol}$. Taken together, none of the 13 patients would have presented with a severe response at $0.219 \mu \mathrm{mol}$. Combining severe responses at each step and mid-step, only 15 of the 449 subjects $(3.3 \%)$ would have presented a severe response of $\triangle \mathrm{FEV}_{1}>40 \%$ (table 2 ) in the suggested abbreviated simulation. Compared to the 11 subjects who had actually experienced a severe response, there was virtually no added risk with the suggested abbreviated three-fold protocol.

The mean \pm SD time needed to perform the usual doubling concentration protocol was $42.4 \pm 9.6 \mathrm{~min}$. If the new tripling protocol proposed on the same subjects

Table 2. - Outcome of the simulated methacholine three-fold dose protocol

\begin{tabular}{lccc}
\hline $\begin{array}{l}\text { Cumulative dose } \\
\mu \mathrm{mol}\end{array}$ & $\begin{array}{c}\text { Total responders i.e. } \\
\Delta \mathrm{FEV} 1>20^{\circ}\end{array}$ & $\begin{array}{c}\text { Moderate responders i.e. } \\
<\Delta \mathrm{FEV} 130-40^{\circ}\end{array}$ & $\begin{array}{c}\text { Severe responders i.e. } \\
\Delta \mathrm{FEV} 1>40^{\circ}\end{array}$ \\
\hline 0.073 & $5^{\S}(3.0)$ & $1(0.2)$ & $2(0.4)$ \\
$0.126^{*}$ & $1^{\S}(0.6)^{*}$ & $00^{*}$ & 0 \\
0.219 & $12(2.7)$ & 0 & 0 \\
$0.379^{*}$ & $17(3.8)^{*}$ & $1(0.2)^{*}$ & $0^{*}$ \\
0.657 & $18(4.0)$ & $6(1.3)$ & $2(0.4)$ \\
$1.137^{*}$ & $35(7.8)^{*}$ & $8(1.8)^{*}$ & $1(0.2)^{*}$ \\
1.970 & $34(7.6)$ & $5(1.1)$ & $4(0.8)$ \\
$3.412^{*}$ & $30(6.7)^{*}$ & $16(3.6)$ & $0^{*}$ \\
5.910 & $42(9.4)$ & $5(1.1)^{*}$ & $4(0.8)$ \\
$10.237^{*}$ & $32(7.1)^{*}$ & $3(0.7)$ & $1(0.2)^{*}$ \\
17.731 & $42(9.4)$ & $52(11.6)$ & $1(0.2)$ \\
Total & $268(59.7)$ & & $15(3.3)$
\end{tabular}

Data are presented as number of subjects (percentage of subjects participating at that dose) at each inhalation step, including intermediate steps (indicated by ${ }^{*}$ ). ${ }^{\S}$ : since only 169 subjects would have participated in these steps, percentages are out of $169 . \triangle \mathrm{FEV} 1$ : the percentage change in forced expiratory volume in one second from baseline. 
Table 3. - Outcomes of the simulated methacholine three-fold dose protocol for separate groups during early protocol steps

\begin{tabular}{|c|c|c|c|c|}
\hline \multirow{2}{*}{$\begin{array}{l}\text { Cumulative dose } \\
\mu \mathrm{mol}\end{array}$} & \multicolumn{2}{|c|}{ FEV1/FVCbl $<0.8(n=169)$} & \multicolumn{2}{|c|}{$\mathrm{FEV} 1 / \mathrm{FVCbl} \geqslant 0.8(\mathrm{n}=280)$} \\
\hline & $\triangle \mathrm{FEV} 130-40 \%$ & $\Delta \mathrm{FEV}_{1}>40 \%$ & $\Delta$ FEV1 $30-40 \%$ & $\Delta \mathrm{FEV}_{1}>40 \%$ \\
\hline 0.073 & $1(0.6)$ & $2(1.2)$ & ND & ND \\
\hline $0.126^{*}$ & $0 *$ & $0 *$ & ND & ND \\
\hline 0.219 & 0 & 0 & 0 & 0 \\
\hline
\end{tabular}

Data are presented as number of subjects (percentage of subjects participating at that dose) at each inhalation step, including intermediate steps (indicated by *). $\triangle \mathrm{FEV} 1$ : the percentage change in forced expiratory volume in one second from baseline; FEV1/FVCbl: baseline ratio of forced expiratory volume to forced vital capacity; ND: not determined.

had been used, the time to perform these 449 challenge tests could have been significantly reduced to 29.6 (8.0) $\min (\mathrm{p}<0.001)$ with a time saving of $30.2 \%$.

\section{Discussion}

All records of $\mathrm{MCh}$ bronchial challenge tests performed in the authors institution during 1996 were analysed retrospectively and it was found that an abbreviated protocol could have been administered to the subjects without increasing the risk of a severe response to any inhalation. According to the new protocol, the initial concentration of $\mathrm{MCh}$ can be $0.219 \mu \mathrm{mol}$ if $\mathrm{FEV} 1 / \mathrm{FVCbl} \geqslant 0.8$, and $0.073 \mu \mathrm{mol}$ if not. Also, it was found that steps between inhalations

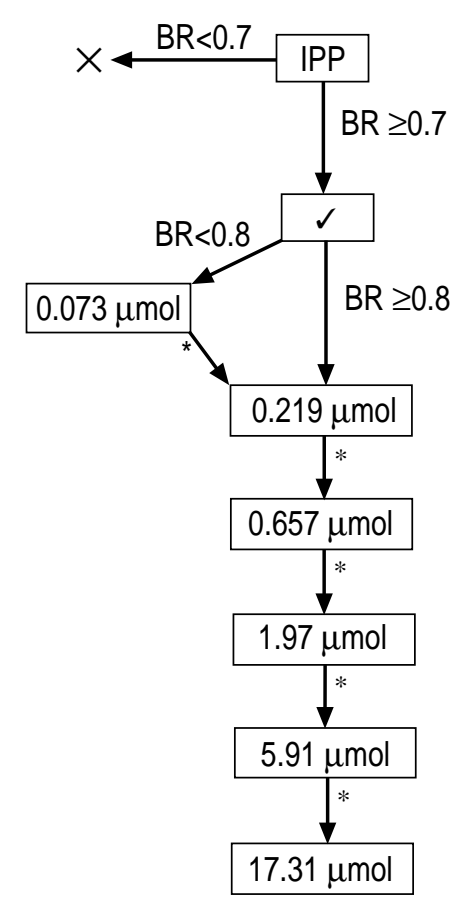

Fig. 1. - Suggested abbreviated protocol. Patients with baseline ratio $(\mathrm{BR}) \geqslant 80 \%$ of predicted, are separated for the initial inhalation step, beyond which the protocol is identical for both groups. *: the next step can follow if the change from baseline forced expiratory volume in one second $(\triangle \mathrm{FEV} 1)<10 \% . \quad \times$ Methacholine Challenge Test (MCT) not performed; $\checkmark$ : MCT performed; IPP: Initial patient population; BR: baseline ratio of forced expiratory volume in one second to forced vital capacity (FEV1/ FVCbl). could be widened beyond the usual doubling concentration. Thus, a protocol consisting of inhalation of a total of five or six delivered doses $(0.073,0.219,0.657$, $1.97,5.91$ and $17.73 \mu \mathrm{mol})$ is as safe as the routine one (these are synonymous to concentrations of $0.07,0.21$, $0.63,1.89$ and $5.67 \mathrm{mg} \cdot \mathrm{mL}^{-1}$ ).

Obviously, any protocol for MCT should strive for a zero risk factor i.e. no risk for a severe response in any subject. In practice, the authors found that even when taking all the necessary precautions when running the routine and supposedly safest protocol, 57 subjects $(20.9 \%)$ were found to have $\triangle \mathrm{FEV} 1>30 \%$ and 11 subjects $(4.0 \%)$ a marked bronchoconstriction i.e. $\triangle \mathrm{FEV}_{1}>40 \%$. A review of short inhalation challenge protocols in the literature shows that a severe bronchonstriction was seen in $3-38 \%$ of the patients, depending on the protocol $[4,8-10,12]$. In the protocol of CHATHAM et al. [10], as many as $38 \%$ of the subjects experienced a severe airway response. At the other end of the range, KREMER et al. [8] observed only $3 \%$ occurrence of severe response. Their reported percentage may be underestimated though, as 38 tests were rejected from the analysis. Hence, the present suggested protocol, yielding only 3.3\% risk of severe response, seems to be one of the safer protocols.

An inhalation challenge protocol can be abbreviated in three ways: 1) by starting at a higher concentration; 2) by using a higher dose-multiplier than the usual doubling concentration protocol; and 3) by decreasing the time of delivering any dose. Most of the abbreviated protocols do not start at a higher initial dose $[4,8,9$, $12,14]$. Indeed, the authors found that patients with airway obstruction $(\mathrm{FEV} 1 / \mathrm{FVCbl}<0.8)$ could be started with only a slightly greater dose $(0.073$ instead of 0.032 umol). In comparison, JUNIPER et al. [14] recommend that the initial concentration be only $0.03 \mathrm{mg} \cdot \mathrm{mL}^{-1}$ in patients treated by corticosteroids (inhaled or ingested). Indeed, the present study found two subjects (out of $169,1.2 \%$ ) who responded at the first inhalation and would have responded severely using the suggested protocol. JUNIPER et al. [14] further suggested that patients in this group with airway obstruction could be started at an initial concentration of $0.125 \mathrm{mg} \cdot \mathrm{mL}^{-1}$ if they were not treated with steroids. The present study found five additional patients $(3.0 \%)$ who had a lower PD20 and would have responded severely at that concentration. Thus, special care needs to be taken when studying these patients in order to avoid a high percentage of severe responses. In addition, since the use of inhaled steroids became the first line of 
treatment, the suggestion of JUNIPER et al. [14] needs to be revised.

Conversely, subjects with no evidence of airway obstruction $(\mathrm{FEV} 1 / \mathrm{FVCbl} \geqslant 0.8)$ could be safely started at a higher initial dose of $0.219 \mu \mathrm{mol}$. JUNIPER et al. [14] suggested that in asthmatic subjects having normal baseline lung function, the initial concentration can be as high as $1 \mathrm{mg} \cdot \mathrm{mL}^{-1}$ if they are maintained on intermittent bronchodilators and $2 \mathrm{mg} \cdot \mathrm{mL}^{-1}$ if they take no medication. In the present study, 19 of 280 subjects $(6.8 \%)$ having an $\mathrm{FEV} 1 / \mathrm{FVCbl} \geqslant 0.8$, reached the end of the challenge at an inhalation concentration of $0.5 \mathrm{mg} \cdot \mathrm{mL}^{-1}$, four of them having a PD20 $<0.219$ $\mu \mathrm{mol}$ (table 2). It is very probable that all 19 would have developed a severe response had they been started at an initial concentration of $1 \mathrm{mg} \cdot \mathrm{mL}^{-1}$. An additional 40 subjects $(14.3 \%)$ responded at that concentration. Thus, the authors do not feel that the recommendations of JUNIPER et al. [14] are safe enough.

Most of the abbreviated protocols used a four-fold or even higher dose-multiplier. In the protocol used by SEARs et al. [15] in an epidemiological setting, the concentration of MCh was increased in ten-fold steps. Simulating the SEARS et al. [15] protocol on the records of patients from the present study, rather than random population, it was calculated that 179 of 449 patients $(40 \%)$ would have reacted with a severe bronchoconstriction (i.e. $\Delta \mathrm{FEV} 1>40 \%$ ). This finding illustrates the importance of tailoring a suitable protocol to the population being studied. Other protocols used fourfold concentration increases [8-10, 12, 14]. Simulating four-fold step increases on the present study's records yielded a $7.5 \%$ rate of severe airway response, substantially greater than the $3.3 \%$ found by the present protocol. The JUNIPER et al. [14] protocol, which was endorsed by the Canadian Thoracic Society and has become quite popular worldwide, is believed to be safe. However, this popular protocol would have yielded a significantly larger number of severe responses than the present suggested protocol (25 versus $15 ; 5.6 \%$ versus $3.3 \%$ ). Moreover, since it practices a switch back to doubling concentration steps if the response of $\triangle \mathrm{FEV} 1$ is $\geqslant 5 \%$ (compared to $\Delta \mathrm{FEV} 1 \geqslant 10 \%$ in the present study), it affords only a $16.5 \%$ saving of time compared to the present $30.2 \%$.

YAN et al. [4] did not clearly describe their abbreviated protocol, only mentioning that they sometimes shortened the test by combining two doses together. Hence, any comparison with this protocol is difficult. Their protocol substantially reduced the time it took to complete the challenge. This was achieved by shortening the time of inhalation by taking one full inspiration lasting $<10 \mathrm{~s}$ compared with the 2 min of tidal breathing in the CHAI et al. [2] protocol. The authors believe that tidal breathing is a more reliable mode of delivery than vital capacity manoeuvres [3, $8-10,12]$, because the tidal breathing manoeuvre is independent of patient cooperation. This is especially true for young children and elderly patients, and may also improve the quality of the results.

Another advantage of the present abbreviated protocol is that the choice of starting MCh concentration relies solely on an objective criterion of baseline lung function, i.e. $\mathrm{FEV} 1 / \mathrm{FVC}$, rather than on any subjec- tive criterion such as a questionnaire. This is in contrast to most of the published abbreviated protocols $[5,6$, $8,9,14-16]$ that were applied only to subjects with no indication of airway hyperresponsiveness and/or asthma, and were based on a questionnaire or taking of clinical history. A questionnaire may become objective only if the set of rules that goes with it is well defined (e.g. a scoring system). No, or even vague, instruction will inevitably result in a subjective determination by the physician at hand. The authors believe that the use of an objective and simple criterion is an important feature in the daily running of a busy referral laboratory, since it simplifies the routine for all personnel involved.

There is the important question of whether or not $\mathrm{MCh}$ inhalations are cumulative and hence, whether PD20 should be reported instead of the provocative concentration causing a 20\% fall in FEV1 (PC20). There is no evidence for cumulative effect when histamine aerosol is inhaled tidally at roughly 5 min interval [17]. However, MCh is metabolized at a slower rate and some accumulation is evident even with a 5 min interval [17]. The authors believe that reporting cumulative doses is more appropriate for MCh challenges when inhalations are given $3 \mathrm{~min}$ apart.

It is noted that the routine doubling concentration protocol calls for halving the dose multiplier when the response to any inhalation is borderline i.e. when $\triangle F_{E V} 1$ is $15-20 \%$. In the present simulation, as in most of the abbreviated protocols [8, 9, 12, 14], a more conservative safety criterion was applied i.e. $\triangle \mathrm{FEV} 1$ of $10-20 \%$. In the study of KREMER et al. [8] and in the Guidelines of the Canadian Thoracic Society [14], this threshold was even lower $(\triangle \mathrm{FEV} 1>6 \%$ and $>5 \%$, respectively). Obviously, such a safety criterion reduces the number of severe responses but also prolongs the test for some patients, thus reducing the overall saving in time. Had the present study used the suggested protocol of JUNIPER et al. [14], time saving would have been a mere $16.5 \%$.

A known disadvantage of long protocols is the lack of cooperation of some patients. A complete MCT takes about one hour to complete during which the subject is required to perform a repetitive task at their best effort. This is an uneasy routine to many, especially young children and elderly patients. This may also be a burden for laboratory technicians who need to constantly coach and encourage the subjects throughout the test. Hence, the suggested abbreviated protocol would not only save time and money, but also improve the quality of the results by improving compliance and motivation of both the patients and technicians. The present recommendations are applicable to all referral pulmonary function laboratories, in which all tests are performed on patients with a clinical picture suggestive of reactive airway disease or on known asthmatics. Contrary to large-scale epidemiological studies of random populations, such centres tend to be more conservative and use a safer protocol on patients that are more difficult to control. The authors believe that the suggested protocol incorporates the need for a shorter and cheaper procedure, yet is sufficiently safe for the target referral laboratories population. 
In conclusion, the present abbreviated methacholine challenge protocol for assessing airway hyperreactivity is advantageous since it is simpler, faster and cheaper to perform than the usual protocol. These benefits were achieved without increasing the potential adverse response of the subjects tested. The authors have started a prospective study in order to validate this new, abbreviated protocol.

Acknowledgements. The authors thank S. Godfrey for his critical review of the manuscript.

\section{References}

1. Hopp RJ, Bewtra AK, Nair NM, Townley RG. Specificity and sensitivity of methacholine inhalation challenge in normal and asthmatic children. $J$ Allergy Clin Immunol 1984; 74: 154-158.

2. Chai H, Farr RS, Froehlich LA, et al. Standardization of bronchial inhalation challenge procedures. J Allergy Clin Immunol 1975; 56: 323-327.

3. Cockcroft DW, Killian DN, Mellon JJA, Hargreave FE. Bronchial reactivity to inhaled histamine: a method and clinical survey. Clin Allergy 1977; 7: 235-243.

4. Yan K, Salome C, Woolcock AJ. Rapid method for measurement of bronchial responsiveness. Thorax 1983; 38: 760-765.

5. Hargreave FE, Ryan G, Thompson NC. Bronchial responsiveness to histamine or methacholine in asthma. J Allergy Clin Immunol 1981; 68: 347-355.

6. Hendrick DJ, Fabbri LM, Hughes JM, et al. Modification of the methacholine inhalation test and its epidemiologic use in polyurethane workers. Am Rev Respir Dis 1986; 133: 600-604.

7. O'Connor G, Sparrow D, Taylor D, Segal M, Weiss S. Analysis of dose-response curves to methacholine. Am Rev Respir Dis 1987; 136: 1412-1417.
8. Kremer AM, Pal TM, Oldenziel M, Kerkof M, de Monchy JG, Rijcken B. Use and safety of a shortened histamine challenge test in an occupational study. Eur Respir J 1995; 6: 737-741.

9. Jorres RA, Nowak D, Kirsten D, Gronke L, Magnussen H. A short protocol for methacholine provocation testing adapted to the Rosenthal-Chai Dosimeter technique. Chest 1997; 111: 866-869.

10. Chatham M, Bleecker ER, Norman P, Smith PL, Mason P. A screening test for airways reactivity. Chest 1982; 82: 15-18.

11. Higgins BG, Britton JR, Chinn S, et al. Comparison of histamine and methacholine for use in bronchial challenge tests in community studies. Thorax 1988; 43: 605-610.

12. Pattemore PK, Asher MI, Harrison AC, Mitchell EA, Rea HH, Stewart AW. The interrelationship among bronchial hyperresponsiveness, the diagnosis of asthma, and asthma symptoms. Am Rev Respir Dis 1990; 142: 549-554.

13. American Thoracic Society. Lung function testing: selection of reference values and interpretative strategies. Am Rev Respir Dis 1991; 144: 1202-1218.

14. Juniper EF, Cockcroft DW, Hargreave FE. Histamine and Methacholine inhalation tests: Tidal breathing method. Laboratory procedure and standardization. 2nd edition. Astra Draco AB, Lund, Sweden, 1994; pp. 33-34.

15. Sears MR, Jones DT, Holdaway MD, et al. Prevalence of bronchial reactivity to inhaled methacholine in New-Zealand children. Thorax 1986; 41: 283-289.

16. Kim YY, Cho SH, Kim WK, et al. Prevalence of childhood asthma based on questionnaires and methacholine bronchial provocation test in Korea. Clin Exp Allergy 1997; 27: 761-768.

17. Juniper EF, Frith PA, Dunnett C, Cockcroft DW, Hargreave FE. Reproducibility and comparison of responses to inhaled histamine and methacholine. Thorax 1987; 33: 705-710. 